Мелем Владимир Владимирович, аспирант кафедры «Эксплуатация МТП, БЖД и ПО», Иркутский государственный аграрный университет имени А.А. Ежевского. Россия.

Степанов Николай Васильевич, канд. техн. наук, доцент кафедры «Эксплуатация МТП, БЖД и ПО», Иркутский государственный аграрный университет имени А.А. Ежевского. Россия.

Боннет Вячеслав Владимирович, канд. техн. наук, доцент кафедры «Электрооборудование и физика», Иркутский государственный аграрный университет имени А.А. Ежевского. Россия.

664038, Иркутская обл., Иркутский $p$-н, п. Молодежный 1/1.

Тел.: (8914) 888-31-13; e-mail: bonnet74@mail.ru.

Ключевые слова: иепной ботводробитель; удаление ботвы; картофель; параметры; мощность.

\title{
THEORETICAL SUBSTANTIATION OF CONSTRUCTIVE PARAMETERS OF THE WORKING BODY OF THE CHAIN TOP-CRUSHER
}

Melem Vladimir Vladimirovich, Post-graduate Studen of the chair "Exploitation of Machine and Tractor Fleet and Safety of Living and Occupational Training" Irkutsk State Agrarian University named after A.A. Izhevskiy. Russia.

Stepanov Nikolay Vasilievich, Candidate of Technical Sciences, Associate Professor of the chair "Exploitation of Machine and Tractor Fleet and Safety of Living and Occupational Training" Irkutsk State Agrarian University named after A.A. Izhevskiy. Russia.

Bonnet Vyacheslav Vladimirovich, Candidate of Technical Sciences, Associate Professor of the chair "Electrical Engineering and Physics”, Irkutsk State Agrarian University named after A. A. Izhevskiy. Russia.

Keywords: chain top-crusher, top removal, potato, parameters; power.
The top-crusher with more advanced design and improved performance characteristics has been proposed. The dependence between geometric and mechanical parameters of the rotor is established, providing maximum absolute speed of knife blades for the moment of cutting the stem which creates the best conditions for grinding the stems. It follows from the results of calculations that the proposed chain top-crusher, in comparison to the existing analogues, has: minimum energy consumption ( $\left.N_{p r v}=13-15 \mathrm{kWt}\right)$, and, consequently, the lower fuel consumption (in comparison to KIR-1.5 $N_{p r v}$ $K I R=18-20 \mathrm{kWt}$ ), improved quality of making technological process - by copying the transverse profile of the ridges and the increased reliability of working bodies.

\author{
ПЛОТНИКОВА Юлия Александровна, Вологодская государственная молочно-хозяйственная \\ академия имени Н.В. Верещзагина
}

ПАЛИЦЫН Андрей Владимирович, Вологодская государственная молочно-хозяйственная академия имени Н.В. Верещагина

коРОтков Александр Николаевич, ООО «СПК «Колхоз Андога»

Проведен анализ вариативных факторов, влияющих на функционирование газогенераторной установки. Выявлено, что наиболее значимым фактором, влияющим на протекание процесса газификации в реакционной зоне газогенератора, обладает режим подачи окислителя - $0_{2}$, качестве которого выступает атмосферный воздух. Предложены и запатентованы элементы параметрического управления подачей окислителя в плоскости и объеме реакционной зоны газогенератора. Рассмотрены основные режимы управления дутьевыми фурмами газогенератора, такие как статический, динамический синхронный и динамический асинхронный. Приведена методика расчета расхода окислителя при различных режимах управления дутьевыми фурмами из условия поддержания скорости истечения воздушного потока из фурмы в оптимальном диапазоне скоростей.

Введение. Вопросы доступности и себестоимости энергетических ресурсов для конечного потребителя являются критическим фактором, определяющим финансовую стабильность технологических производственных циклов и предприятия в целом. Проведенный литературный обзор и анализ международных патентных баз данных по направлению энергетических технологий переработки отходов и энергетическому использованию местных биоресурсов показали, что существенных, «революционных» технических и технологических 
изменений в конструкциях газогенераторных установок с середины XX в. не произошло. При этом наблюдается «эволюция» элементов и систем газогенераторных установок. Применяются современные конструкционные материалы, используются методы механизации и автоматизации приготовления, загрузки и дозированной подачи топлива, идущего на газификацию, и т.д. Следует отметить, что одной из существенных инноваций в конструкции газогенераторных установок стала система контроля с использованием промышленного контролера, разработанная группой американских изобретателей. Она получила практическую реализацию в газогенераторных конструкторах Gasifier Experimenters Kit (the GEK). Также исследования по газогенераторной тематике проводятся в Индии, Китае и в некоторых странах Европейского союза, среди которых есть работы не только обобщающе - теоретического, но и экспериментального характера. Следующим логическим шагом в эволюции газогенераторных установок должно стать управление самим процессом газификации твердого топлива в газогенераторе.

Цель исследования - провести обоснование возможности оптимизации основных конструктивно-технологических параметров газогенераторной установки при ее функционировании на местных энергетических ресурcax, в том числе промышленных и сельскохозяйственных отходах при совместной работе с ДВС электростанции.

Методика исследований. В ходе исследований был проведен анализ вариативных факторов, влияющих на функционирование газогенераторной установки, выделены наиболее значимые из них; рассмотрены режимы управления газогенераторной установкой с учетом анализа вариативных факторов.

Результаты исследований. Газогенераторные технологии позволяют производить из растительной биомассы, карбоносодержащих отходов сельскохозяйственного и индустриальных производств газообразное топливо, которое в дальнейшем может быть использовано в технологических процессах для получения тепловой энергии или в качестве моторного топлива для ДВС. Процесс газификации, протекающий в газогенераторе при высоких температурах и контролируемом недостатке окислителя $\mathrm{O}_{2}$, представляет из себя достаточно сложный, многофакторный химический процесс разрушения и частичного окисления сложных многокомпонентных соединений, их химических связей. В результате этого образуются простые химические соединения $\left(\mathrm{CO}_{2}\right.$,
$\mathrm{CO}, \mathrm{H}_{2}, \mathrm{CH}_{4}, \mathrm{H}_{2} \mathrm{O}$ и т. д.) и выделяется некоторое количество тепловой энергии, так как суммарный тепловой баланс процесса положительный. Кроме основного продукта газогенераторной технологии - горючего генераторного газа и побочного - тепловой энергии, сопровождающей процесс его производства, конечным продуктом переработки растительной биомассы и карбоносодержащих отходов является концентрированное минеральное удобрение - зола $[2,3,6,10]$.

Для получения генераторного газа в качестве моторного топлива для ДВС, как правило, используют газогенераторные установки с обращенным процессом газификации. Коммерческий интерес представляют газогенераторные установки для питания генераторным газом ДВС электростанций. Данные технологии находятся в стадии экспериментальных разработок и опытных образцов. Работы по этому направлению ведутся во многих странах мира $[3,11,12]$.

Несмотря на все многообразие видов и типов газогенераторных установок, процесс преобразования твердого топлива в газообразное характеризуется одними и теми же химическим реакциями [2]:

$$
\begin{gathered}
\mathrm{C}+\mathrm{O}_{2} \rightarrow \mathrm{CO}_{2}+409 \text { МДж } \\
2 \mathrm{C}+\mathrm{O}_{2} \rightarrow 2 \mathrm{CO}+247 \text { МДж } \\
2 \mathrm{CO}+\mathrm{O}_{2} \rightarrow 2 \mathrm{CO}_{2}+572,5 \text { МДж } \\
\mathrm{CO}_{2}+\mathrm{C} \rightarrow 2 \mathrm{CO}-162 \mathrm{MДж} \\
\mathrm{C}+\mathrm{H}_{2} \mathrm{O} \rightarrow \mathrm{CO}+\mathrm{H}_{2}-118,8 \mathrm{MДж} \\
\mathrm{C}+2 \mathrm{H}_{2} \mathrm{O} \rightarrow \mathrm{CO}_{2}+2 \mathrm{H}_{2}-75,5 \text { МДж } \\
\mathrm{CO}+\mathrm{H}_{2} \mathrm{O} \rightarrow \mathrm{CO}_{2}+\mathrm{H}_{2}+43,7 \text { МДж } \\
\mathrm{CO}_{2}+3 \mathrm{H}_{2} \rightarrow \mathrm{CH}_{4}+\mathrm{H}_{2} \mathrm{O}+206,5 \text { МДж } \\
2 \mathrm{CO}+\mathrm{H}_{2} \rightarrow \mathrm{CH}_{4}+\mathrm{CO}_{2}+248 \text { МДж }
\end{gathered}
$$

К основным факторам, оказывающим значительное влияние на процесс газификации, можно отнести: выбранный тип процесса газификации (прямой, обращенный или поперечный), конструктивные параметры газогенератора, вид топлива, температуру по рабочим зонам газогенератора, способ подачи и скорость истечения воздушной струи из фурмы (воздушного жиклера) в реакционную зону газогенератора, расход генераторного газа $[1,3,6,13,14]$.

Проведенный анализ вышеприведенных химических реакций, сопровождающих процесс преобразования твердого топлива в газообразное, позволяет сделать вывод, что первичными являются окислительные реакции (1), (2), (3), (7), (8), (9). При этом тепловой 
баланс процесса положительный (т.к. реакции экзотермические). Восстановительные реакции (4), (5), (6) будут вторичными, так как они происходят с поглощением теплоты (эндотермические реакции). Вследствие этого процессом газификации в газогенераторной установке можно управлять не только за счет конструктивных параметров газогенератора, расхода генераторного газа, вида газифицируемого твердого топлива, но также за счет количества и способа (режима) подачи окислителя $\left(\mathrm{O}_{2}\right)$ в реакционную зону газогенератора $[4,7,8]$.

Конструктивно-технологические параметры газогенераторов традиционных конструкций рассчитывают по типовым методикам, исходя из максимального расхода генераторного газа потребителем. Далее производят расчет необходимого количества окислителя для функционирования газогенератора. Выбирают количество и диаметр дутьевых фурм, с учетом оптимальной скорости истечения окислителя. В своих исследовательских работах авторы дают различные количественные оценки оптимальной скорости окислителя из дутьевой фурмы. Но все они сходятся в одном, что скорость истечения окислителя из дутьевой фурмы в реакционную зону газогенератора является одним из ключевых факторов, влияющих на процесс газификации и состав генераторного газа $[3,5,6,13,14]$.

Приняв за отправную точку в исследованиях гипотезу о ключевом влиянии скорости истечения окислителя из дутьевой фурмы газогенератора на процесс газификации с учетом поисковых исследований предложены и запатентованы элементы параметрического управления подачей окислителя из дутьевой фурмы в плоскости и объеме реакционной зоны газогенератора [7, 8].

Рассмотрим возможные режимы управления дутьевыми фурмами на примере газогенератора с параметрическим регулированием рабочего процесса в плоскости фурменного пояса [7]. Газогенератор с параметрическим регулированием рабочего процесса в плоскости фурменного пояса представлен в качестве наиболее простого примера, иллюстрирующего функциональные возможности предлагаемой технологии. Газогенератор с параметрическим регулированием рабочего процесса в объеме фурменного пояса фактически представляет собой синтез плоскостного регулирования с поправкой на синергетический эффект взаимодействия между рядами дутьевых фурм в объеме фурменного пояса при их совместном функционировании. При этом расчет его рабочих параметров выполняется аналогично и особых затруднений не вызывает.

В газогенераторе с параметрическим регулированием рабочего процесса в плоскости фурменного пояса возможно осуществить три основных режима функционирования дутьевых фурм.

1. Статический режим функционирования. В зависимости от расхода генераторного газа в работе задействовано различное количество дутьевых фурм $k$. При этом скорость истечения воздуха из дутьевой фурмы газогенератора изменяется в пределах $\pm \Delta v$ от оптимальной скорости. В общем виде идеализированный график расхода воздуха, проходящего через дутьевые фурмы газогенератора, в зависимости от их работающего количества приведен на рис. 1.

2. Динамический, синхронный режим функционирования. В зависимости от расхода генераторного газа в работе задействовано одинаковое количество дутьевых фурм. При этом дутьевые фурмы одновременно включаются и выключаются в работу (т.е. работают синхронно). Изменяя соотношение между временем работы и временем отключения фурмы (т.е. регулируя скважность), можно регулировать объем и скорость истечения воздуха из дутьевой фурмы газогенератора. Идеализированный график расхода воздуха, проходящего через дутьевые фурмы газогенератора, в зависимости от режима их работы, приведен на рис. 2.

3. Динамический, асинхронный режим функционирования. В зависимости от расхода генераторного газа в работе задействовано одинаковое количество дутьевых фурм. При этом дутьевые фурмы включаются и выключаются в работу со смещением во времени друг относительно друга (т.е. работают асинхронно). Изменяя соотношение между временем работы и временем отключения фурмы (т.е. регулируя скважность), можно регулировать объем и скорость истечения воздуха из дутьевой фурмы газогенератора. Смещение во времени включения дутьевых фурм показано на рис. 3. График расхода воздуха, проходящего через дутьевые фурмы газогенератора, в зависимости от режима их работы приведен на рис. 4.

Управление воздушным потоком, проходящим через дутьевую фурму, осуществляется посредством воздушного электромагнитного клапана. Статический расход воздуха $G_{\text {в.ст }}$, кг/ч, через воздушный электромагнитный клапан может быть определен по формуле [10]: 


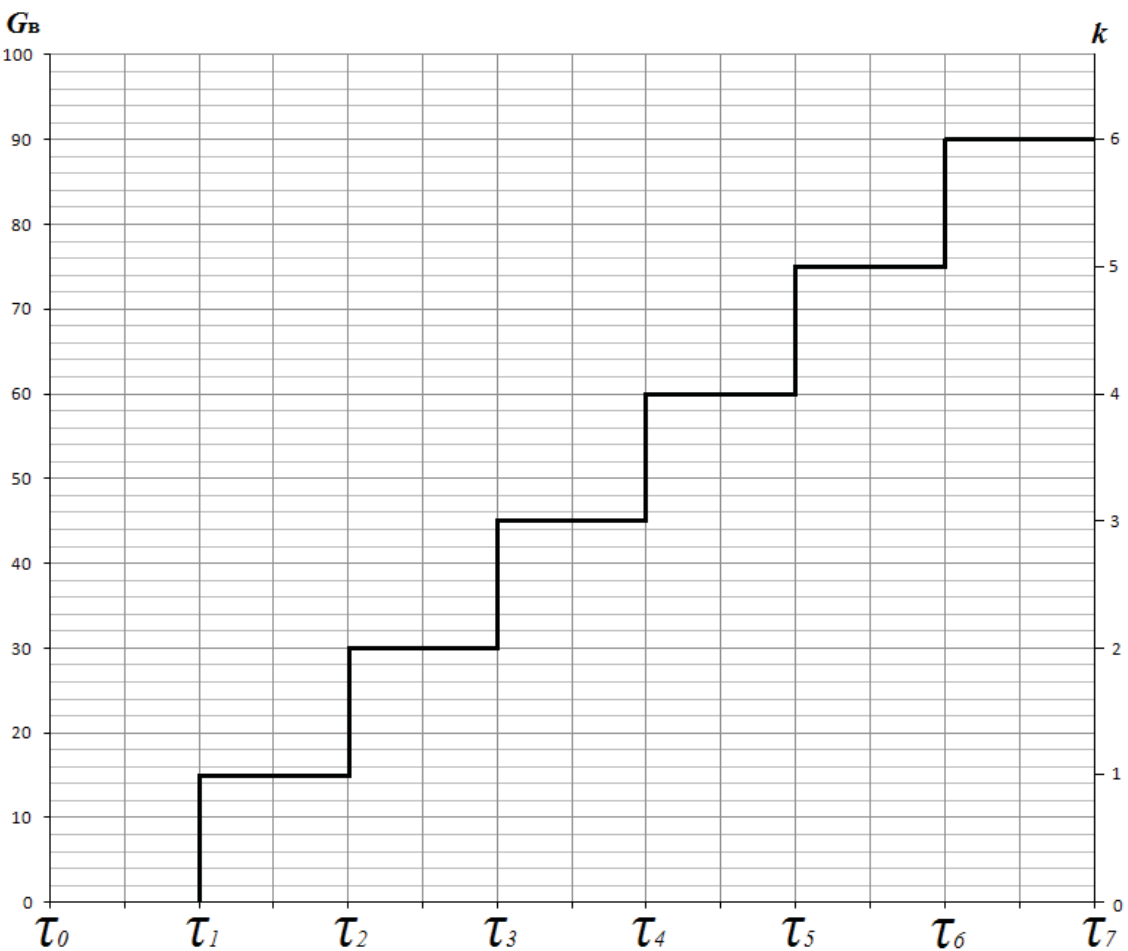

Рис. 1. Идеализированный график расхода воздуха в зависимости от количества задействованных дутьевых фурм

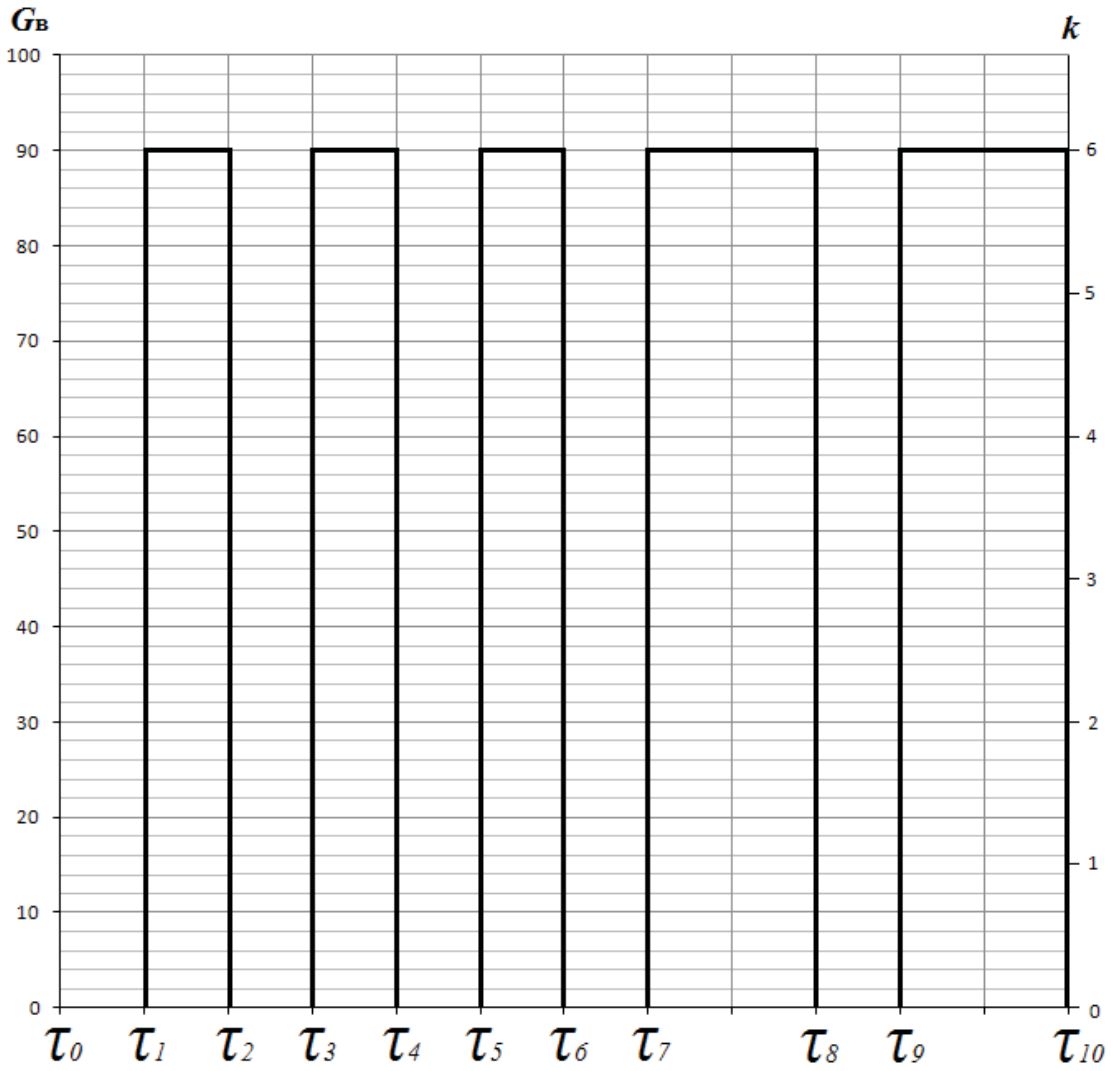

Рис. 2. Идеализированный график расхода воздуха через дутъевые фурмы при динамическом, синхронном режиме их работы

$$
G_{\mathrm{E} . \mathrm{CT} .}=\frac{529 K_{v}}{\sqrt{\frac{T_{1}}{\Delta P P_{2} \gamma_{\mathrm{B}}}}}
$$

где $K_{\mathrm{v}}$ - коэффициент условной пропускной способности воздушного электромагнитного клапана; $T_{1}$ - температура среды до клапана, ${ }^{\circ} \mathrm{K} ; \Delta P-$ перепад давления на клапане, кгс $/ \mathrm{cm}^{2} ; P_{2}$ - абсолютное давление среды после клапана, кгс $/ \mathrm{cm}^{2} ; \gamma_{\text {в }}$ - плотность вхо- дящего воздуха, кг $/ \mathrm{M}^{3}$, при $t_{0}=0{ }^{\circ} \mathrm{C}$ и $B_{\mathrm{a}}=$ $=101,32472$ кПа.

Идеализированные графики расхода воздуха для процесса газификации твердого топлива в газогенераторе являются весьма условными, так как не учитывают индивидуальные особенности электромагнитных воздушных клапанов, гидравлическое сопротивление газогенераторной установки, физико-механи- 


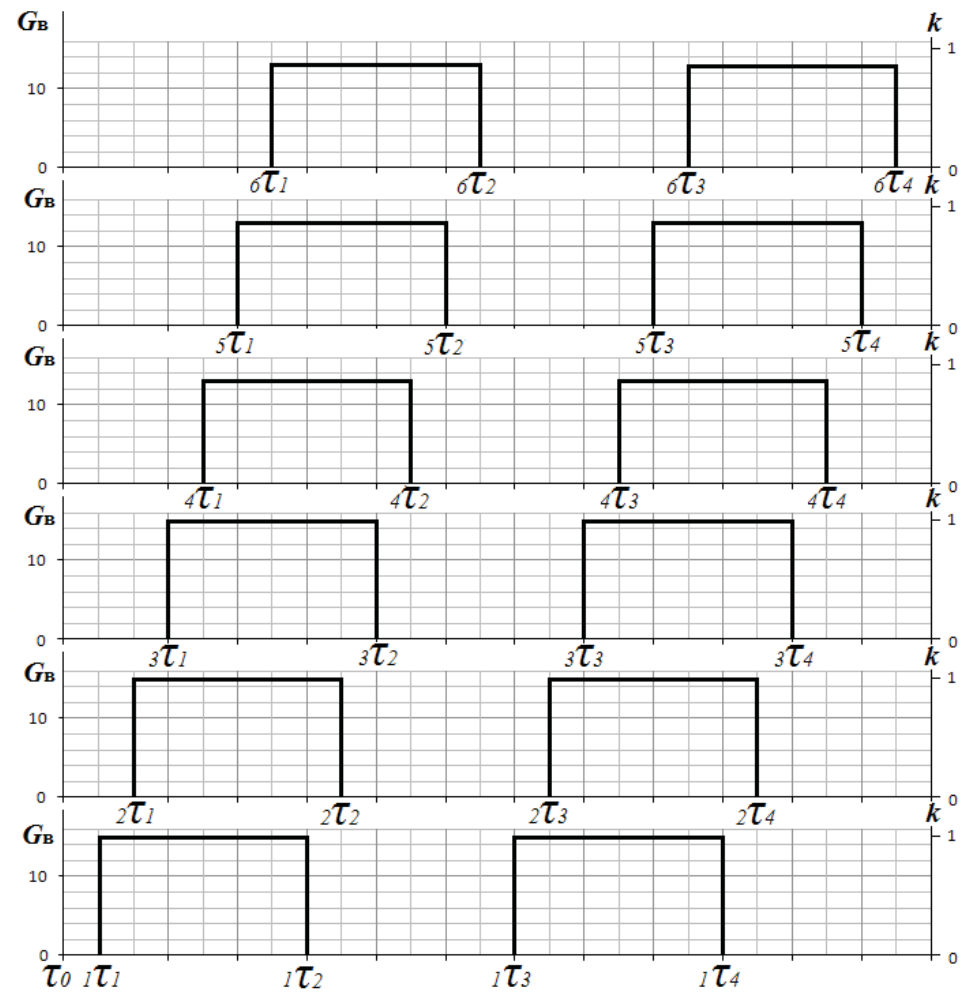

Рис. 3. График смещения во времени включения дутьевых фурм при динамическом, асинхронном режиме их работы

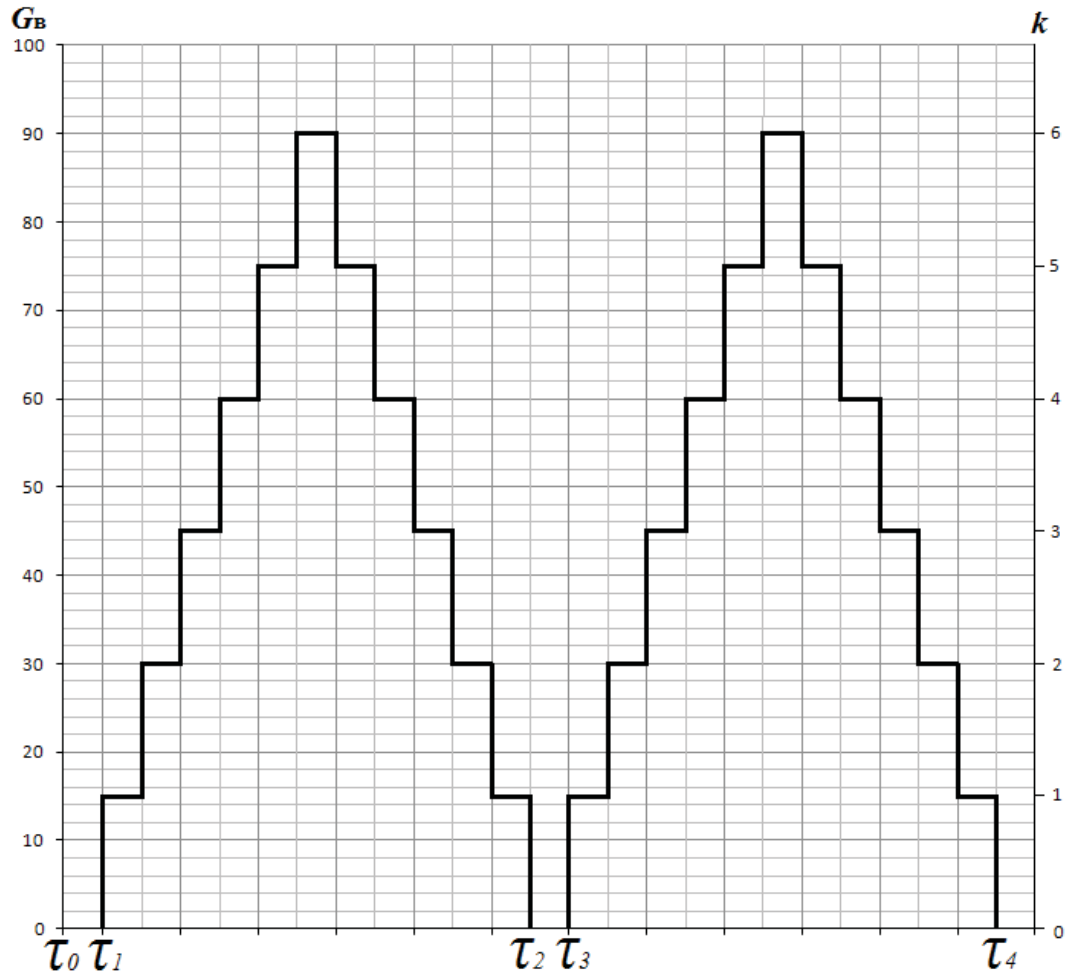

Рис. 4. Идеализированный график расхода воздуха через дутъевые фурмы при динамическом, асинхронном режиме их работы

ческий состав твердого топлива, идущего на газификацию (гидравлическое сопротивление реакционного слоя топлива). Предполагаемый реальный график расхода воздуха через воздушный электромагнитный клапан, управляющий дутьевой фурмой, представим в следующем виде (рис. 5).

Для упрощения математической записи и вычисления в дальнейшем подынтегральной функции произведем замену выражения $G_{\text {в.ст }}$ на рав- нозначную тождественную функцию $f(x)$. Исходя из графика (см. рис. 5), расход воздуха через воздушный электромагнитный клапан за единичный цикл его работы, а следовательно, и через дутьевую фурму определим как площадь, ограниченную кривой графика:

$$
G_{\mathrm{\varepsilon}}=\int_{\tau_{1}}^{\tau_{4}} f(x) d x .
$$

Тогда расход воздуха через дутьевую фурму 


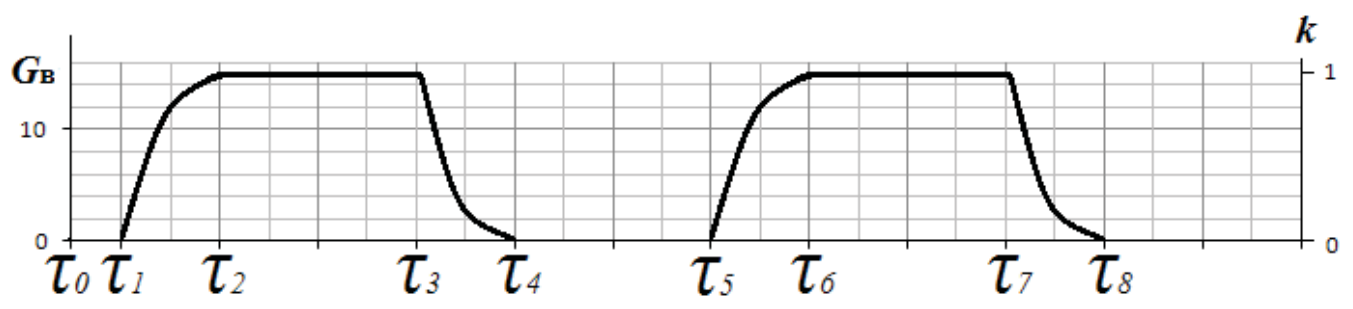

Рис. 5. График реального расхода воздуха через воздушный электромагнитный клапан

за 1 ч ее работы найдем по формуле, обозначив количество циклов работы через $m$ :

$$
G_{\mathrm{z}}=\sum_{i=0}^{m-1} \int_{\tau_{4 i+1}}^{\tau_{4 i+4}} f(x) d x,
$$

где $\tau$ - размерность времени, ч; $m$ - количество циклов работы дутьевой фурмы за период времени, $m=1$ ч.

Для группы дутьевых фурм, функционирующих в динамическом, синхронном режиме, суммарный расход воздуха $\sum G_{\text {в }}$, кг/ч, определим как сумму расхода воздуха через каждую дутьевую фурму за $m$ циклов ее работы:

$$
\begin{array}{r}
\Sigma G_{\mathrm{g}}=k_{1 \mathrm{k} \Omega \pi} \sum_{i=0}^{m-1} \int_{\tau_{4 i+1}}^{\tau_{4 i+4}} f(x) d x+ \\
+k_{2 \mathrm{kл}} \sum_{i=0}^{m-1} \int_{\tau_{4 i+1}}^{\tau_{4 i+4}} f(x) d x+\cdots \\
+k_{p \text { к л }} \sum_{i=0}^{m-1} \int_{\tau_{4 i+1}}^{\tau_{4 i+4}} f(x) d x,
\end{array}
$$

где $k_{\text {р.кл }}$ - поправочный коэффициент, характеризующий индивидуальные особенности воздушного электромагнитного клапана, управляющего дутьевой фурмой; $p$ - номер воздушного электромагнитного клапана управляющего дутьевой фурмой.

Проведя преобразование формулы (14), получим:

$$
\begin{aligned}
\Sigma G_{\mathrm{g}}= & \sum_{i=0}^{m-1} \int_{\tau_{4 i+1}}^{\tau_{4 i+4}} f(x) d x\left(k_{1 \mathrm{k} \pi \mathrm{r}}+\right. \\
& \left.+k_{2 \mathrm{k} \pi}+\cdots+k_{p_{\mathrm{k} \pi}}\right) .
\end{aligned}
$$

С учетом времени единичного цикла за 1 ч работы количество циклов работы группы дутьевых фурм, функционирующих в динамическом, синхронном режиме $m$, рассчитывается из соотношения

$$
m=\left(\frac{1}{\tau_{4}-\tau_{1}}\right)
$$

Для группы дутьевых фурм, функционирующих в динамическом, асинхронном режиме, суммарный расход воздуха $\sum G_{\text {в }}$ кг/ч, найдем как сумму расхода воздуха через каждую дутьевую фурму за $m$ циклов ее работы:

$$
\Sigma G_{\mathrm{g}}=k_{1 \mathrm{k \pi}} \sum_{i=0}^{m-1} \int_{\tau_{4 i+1}}^{\tau_{4 i+4}} f(x) d x+
$$

$$
\begin{aligned}
& +k_{2 \mathrm{k} \pi} \sum_{i=0}^{m-1} \int_{\tau_{4 i+1}+\Delta \tau}^{\tau_{4 i+4}+\Delta \tau} f(x) d x+ \\
& +k_{3 \mathrm{k} \pi} \sum_{i=0}^{m-1} \int_{\tau_{4 i+1}+2 \Delta \tau}^{\tau_{4 i+4}+2 \Delta \tau} f(x) d x+\cdots \\
& +k_{p \text { к } \pi} \sum_{i=0}^{m-1} \int_{\tau_{4 i+1}+(p-1) \Delta \tau}^{\tau_{4 i+4}+(p-1) \Delta \tau} f(x) d x,
\end{aligned}
$$

где $p$ - номер воздушного электромагнитного клапана, управляющего дутьевой фурмой; $\Delta$ - шаг времени асинхронного включения и выключения клапана, управляющего дутьевой фурмой.

Полученные математические зависимости для расчета расхода воздуха при параметрическом управлении дутьевыми фурмами газогенератора (13), (14) и (16) не учитывают коэффициент сопротивления слоя топлива в реакционной зоне газогенератора. Данный параметр может быть определен только экспериментальным путем, так как физико-механические свойства идущего на газификацию твердого топлива могут иметь существенные различия (фракционный состав, адгезивные свойства и т.д.), вследствие чего сопротивление реакционной зоны газогенератора также будет изменяться.

Заключение. Анализ научно-технической литературы по газогенераторной тематике позволяет сделать вывод, что скорость истечения воздуха из дутьевой фурмы газогенератора является переменной величиной в процессе работы газогенераторной установки, при этом она оказывает существенное влияние на качественный состав генераторного газа и динамические характеристики ДВС.

Теоретические исследования позволяют сделать вывод о возможности практического применения параметрического регулирования процессом газификации за счет изменения количества и способа (режима) подачи окислителя $\left(\mathrm{O}_{2}\right)$ в реакционную зону газогенератора. Полученные математические зависимости для расчета расхода воздуха при различных режимах управления дутьевыми фурмами газогенератора нуждаются в практической апробации на лабораторных установках для экспериментального выявления функциональных зависимостей и поправочных коэфициентов. 
В заключение следует отметить, что система параметрического управления воздухом в газогенераторе за счет варьирования времени цикла работы и паузы в работе электромагнитного воздушного клапана требует использования не только аппаратных, но и программных средств, что в конечном итоге завязывает систему управления на электронный модуль управления.

\section{СПИСОК ЛИТЕРАТУРЫ}

1. Алешина А.С. Газификация растительной биомассы в газогенераторах кипящего слоя: дис. ... канд. техн. наук. - СПб., 2013. - 165 с.

2. Большая советская энциклопедия: в 30 т. / гл. ред. А. М. Прохоров. - 3-е изд. - М.: Сов. энцикл., 1969-1978.

3. Интернет-ресурс компании Gasifier Experimenters Kit (the GEK). - Режим доступа: www.gekgasifier.com.

4. Коротков А.Н. Совершенствование конструкции и оптимизация конструктивно-технологических параметров газогенераторной установки: научно-квалификационная работа на соискание степени: «Исследователь. Преподаватель-исследователь». Направление подготовки 35.06.04: «Технологии, средства механизации и энергетическое оборудование в сельском, лесном и рыбном хозяйстве». - Вологда - Молочное, 2018. - 132 с.

5. Лямин В.А. Газификация древесины. - М., 1967. -262 c.

6. Мезин И.С. Транспортные газогенераторы. M., 1948. - $310 \mathrm{c}$.

7. Пат. 2555486, Российская Федерация, C10J3/20 (2006.01). Газогенератор / В.Н. Острецов, А.С. Зубакин, А.В. Палицын, А.Н. Коротков. № 2013132317; заявл. 11.07.2013; опубл. 10.07.2015, Бюл. № 19.

8. Пат. 2575536, Российская Федерация, С10J3/20 (2006.01). Газогенератор / В.Н. Острецов, А.С. Зубакин, А.В. Палицын, А.Н. Коротков, Ф.А. Киприянов,
А. С. Рассветалов. № 2014132727; заявл. 7.08.2014; опубл. 20.02.2016, Бюл. № 5.

9. Рабочий лист для расчета клапанов AB $04 \mathrm{RU}$ SAMSON AG MESS - UND REGELTECHNIK Издание: август 2011. - Режим доступа: http://www.samson.de.

10. Справочник по удобрениям. - М.: Колосс, 1964. - 719 с.

11. Чувашев В.Н., Иппатов С.Ф. Применение газогенераторных установок в сельскохозяйственном производстве // Вестник ВНИИМЖ. - 2017. №4(28). - C. 88-91.

12. Basu P. Biomass gasification and pyrolysis: Prakctical design and theory. Elsevier, 2010, 364 p.

13. Thomas B. Reed. Generator Gas. The Swedish Experience - Gas 1939 - 1945 // Biomass Energy Foundation, 1998, $334 \mathrm{p}$.

14. Werner Kroll. Der Gasgenerator // Herausgegeben vom Verlag G. Kliemt, Nossen i. Sa. Berlin, 1943, $208 \mathrm{p}$.

Плотникова Юлия Александровна, канд. физ.-мат.наук, доцент кафедры «ехнические системы в агробизнесе», Вологодская государственная молочно-хозяйственная академия имени Н.В. Верещагина. Россия.

Палицын Андрей Владимирович, канд. техн. наук, доцент кафедры «Технические системы в агробизнесе», Вологодская государственная молочно-хозяйственная академия имени Н.В. Верещагина. Россия.

160555, Вологодская обл., г. Вологда, с. Молочное, ул. Шмидта, 2.

Тел.: (8172) 52-57-30.

Коротков Александр Николаевич, главный инженер, ООО «СПК «Колхоз Андога». Россия.

162520, Вологодская обл., Кадуйский $p$-н, n/o Стан, с. Никольское, ул. Городская, 2.

Тел.: (81742) 3-41-38.

Ключевые слова: возобновляемые источники энергии; отходы производства; газогенератор; генераторный газ; параметрическое управление.

\section{OPTIMIZATION OF DESIGN AND TECHNOLOGICAL PARAMETERS OF THE GAS-PRODUCER PLANT FOR OPERATING THE INTERNAL COMBUSTION ENGINE OF THE POWER PLANT}

Plotnikova Yuliya Aleksandrovna, Candidate of Physical and Mathematical Sciences, Associate Professor of the chair "Technical Systems in Agribusiness", Vereshchagin State Dairy Farming Academy of Vologda. Russia.

Palitsyn Andrey Vladimirovich, Candidate of Technical Sciences, Associate Professor of the chair "Technical Systems in Agribusiness", Vereshchagin State Dairy Farming Academy of Vologda. Russia.

Korotkov Aleksandr Nikolaevich, Chief Engineer, Andoga Collective Farm agricultural production cooperative. Russia.

Keywords: renewable energy sources; waste products; gasifier; generator gas; parametric control.

The analysis of variable factors affecting the gas- producer plant functioning has been carried out. The study has shown that the most significant factor affecting the gasification process in the reaction zone of the gasifier is the supply mode of $O_{2}$ oxidizing agent, which is the atmospheric air. Having taken into account the results of the exploratory studies, the authors have patented and proposed parametric control elements of the oxidizing agent supply in the plane and volume of the gasifier reaction zone. The article deals with the basic control modes of the blast lances of the gasifier, such as static, dynamic synchronous and dynamic asynchronous ones. The method of calculation of the oxidizer flow rate under different control modes of the blast lances, under condition of maintaining the rate of airflow out of the lance in the optimal range of speeds is given. 